\title{
Estabilidade sensorial de suco de maracujá pronto para beber acondicionado em latas de aço
}

Sensorial stability of ready-to-drink passion fruit juice packaged in tinplate cans

\author{
Elisabete Segantini SARON ${ }^{1 *}$, Sílvia Tondella DANTAS ${ }^{1}$, Hilary Castle de MENEZES ${ }^{2}$, \\ Beatriz Maria Curtio SOARES ${ }^{1}$, Michelle Fernandes NUNES ${ }^{1}$
}

\begin{abstract}
Resumo
O estudo teve por objetivo avaliar a preservação das características sensoriais e físico-químicas de suco de maracujá pronto para beber acondicionado em latas de três peças em folha-de-flandres eletrossoldadas, com diferentes condições de envernizamento interno do corpo e costura lateral, através de teste de estocagem. O suco de maracujá foi acondicionado em latas com camada nominal interna de $2,0 \mathrm{~g}$ de $\mathrm{Sn} . \mathrm{m}^{-2}$, com três sistemas de revestimento orgânico interno e condicionado a 25 e $35{ }^{\circ} \mathrm{C}$ durante 360 dias. Ocorreu um acentuado decréscimo do conteúdo de ácido ascórbico até os 180 dias, mantendo-se estável até 360 dias em todas as condições estudadas. A avaliação de cor demonstrou o escurecimento do suco até os 120 dias e posteriormente sua descoloração, entre os 300 e 360 dias, nas duas temperaturas estudadas. A avaliação sensorial durante a estocagem demonstrou desempenho similar para todas as latas, sendo inferior apenas para a lata Pó a $35{ }^{\circ} \mathrm{C}$. As principais alterações verificadas no produto ao longo da estocagem foram associadas às alterações intrínsecas à bebida e não à interação suco/embalagem. O estudo permitiu concluir que os três sistemas de envernizamento das latas estudadas podem ser utilizados no acondicionamento de suco de maracujá pronto para beber para uma vida-de-prateleira mínima de 12 meses.
\end{abstract}

Palavras-chave: suco de maracujá; embalagens metálicas; qualidade sensorial; carotenóides; ácido ascórbico; estabilidade.

\begin{abstract}
The purpose of this work was to evaluate the preservation of the sensorial and physicochemical characteristics of ready-to-drink passion fruit juice packaged in three-piece welded tinplate cans with different internal coatings of the body and side strips, based on a storage test. The product evaluated was ready-to-drink passion fruit juice packaged in cans with an internal layer of 2.0 g.m $\mathrm{m}^{-2}$ of tin, with three inner organic coating systems, stored at 25 and $35{ }^{\circ} \mathrm{C}$ for 360 days. A sharp decrease in ascorbic acid content was recorded up to day 180 , after which it remained constant until the end of the storage period at the two aforementioned temperatures and in all the types of cans studied. The color evaluation showed the juice browning before 120 days of storage, and subsequent discoloration between 300 and 360 days, at the two storage temperatures. The sensorial analysis during storage indicated a similar performance for all the cans, which was lower only in the case of one packaging variable. The main changes recorded during the storage period were associated with inherent modifications of the beverage itself and not to juice/packaging interaction. This study led to the conclusion that all the types of packaging under study are suitable for ready-to-drink passion fruit juice for a minimum shelf-life of 12 months.

Keywords: passion fruit juice; metallic packaging; sensorial quality; carotenoids; ascorbic acid; stability.
\end{abstract}

\section{Introdução}

O suco de maracujá é caracterizado por apresentar sabor e aroma intensos, possui um conteúdo em sólidos solúveis ao redor de $15 \%$ e alta acidez, com uma relação média entre ${ }^{\circ}$ Brix/acidez de 5 . Os ácidos orgânicos presentes no maracujá são importantes na definição de seu flavor tão característico. O pH no maracujá roxo varia de 2,6 a 3,2 e no amarelo de 2,8 a 3,3 e o teor total de ácidos de 2,4 a $4,8 \%$ e 3,0 a 5,0\%, respectivamente, sendo que 93 a $96 \%$ da sua acidez total é constituída por ácido cítrico. A coloração do suco se deve a um complexo de pigmentos carotenóides, no qual predomina o $\beta$-caroteno ${ }^{12}$.

O suco de maracujá apresenta uma importante possibilidade de crescimento na comercialização e consumo de sucos prontos para beber, uma vez que o maracujá é uma fruta

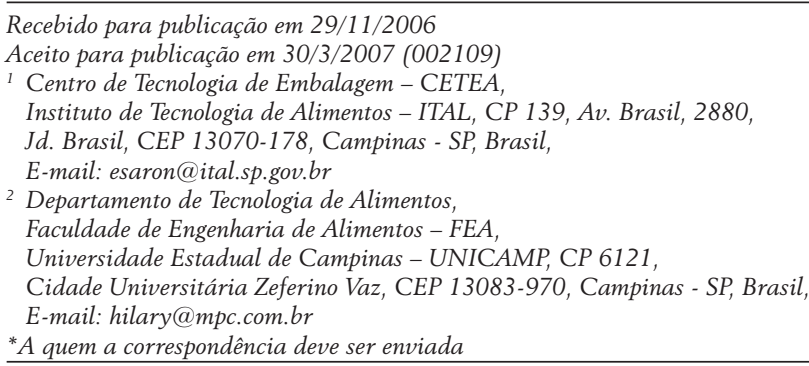

típica brasileira, disponível em abundância ao longo do ano. Por ser representante da classe de frutas ácidas, este tipo de suco apresenta características agressivas ao material metálico, requisitando uma adequada especificação de envernizamento interno, principalmente da região de proteção da área de soldagem (denominada side stripe), para manutenção das suas propriedades sensoriais e garantia da sua vida-de-prateleira.

O mercado brasileiro de sucos prontos tem se mostrado o segmento de maior crescimento na categoria das bebidas não-alcoólicas nos últimos anos, onde há previsões de que as exportações de sucos de frutas devam dobrar nos próximos $\operatorname{anos}^{8,10}$. No ano de $2004,81,8 \%$ dos sucos e néctares processados foram comercializados em embalagens cartonadas assépticas, 16,5\% comercializados em latas de alumínio de duas peças e cerca de 1,7\% em embalagens de vidro. A projeção de consumo do segmento de sucos e néctares processados para 2006 é de 600,8 milhões de litros ${ }^{3}$. Embora não sejam utilizadas no Brasil para acondicionamento de sucos prontos para beber, as embalagens em aço de três peças representam uma interessante alternativa de embalagem para esses produtos, desde que a proteção do material metálico, por meio de vernizes, ocorra de forma adequada.

A interação lata de aço/alimento, considerando-se o enlatamento de produtos ácidos, é caracterizada principalmente pela 
dissolução dos metais que constituem a embalagem, o ferro e o estanho, quando do uso de folhas-de-flandres e ferro e cromo, quando do uso de folhas cromadas ${ }^{4}$, o que pode levar a uma alteração das características sensoriais do produto, podendo limitar a sua vida-de-prateleira.

\section{Material e métodos}

\subsection{Materiais}

Foi estudado o suco de maracujá pronto para beber, produzido em escala industrial, composto por suco concentrado de maracujá, água, açúcar líquido, ácido cítrico e ácido ascórbico. O suco foi pasteurizado em um trocador de calor de placas, marca ISUME Food Manufacture, por 30 segundos a $91{ }^{\circ} \mathrm{C} \pm 1{ }^{\circ} \mathrm{C}$, seguindo-se de acondicionamento em latas de folhas-de-flandres à temperatura de $89{ }^{\circ} \mathrm{C} \pm 1{ }^{\circ} \mathrm{C}$, fechamento das latas e resfriamento por 12 minutos. $\mathrm{O}$ mesmo produto foi acondicionado assepticamente em embalagem cartonada Tetra Brik ${ }^{\circledast}$ Aseptic e mantido congelado em câmara a $-20{ }^{\circ} \mathrm{C}$ para ser utilizado como referência nas avaliações sensoriais durante o estudo de estocagem.

As latas de três peças utilizadas para o acondicionamento do suco de maracujá foram produzidas com corpo em folhade-flandres (2,0 g Sn. $\left.\mathrm{m}^{-2}\right)$, fundo em folha cromada e tampa em alumínio, em três versões de envernizamento interno, denominadas Normal, Repair e Pó, cuja descrição do envernizamento encontra-se detalhada na Tabela 1.

As latas denominadas Normal, Repair e Pó possuíam camada seca de verniz no corpo de 14,1 g.m $\mathrm{m}^{-2}, 14,2$ g.m $\mathrm{m}^{-2}$ e 5,8 g.m $\mathrm{m}^{-2}$, respectivamente, enquanto a região do side stripe apresentava 31,2 g.m $\mathrm{m}^{-2}, 36,6$ g.m $\mathrm{m}^{-2}$ e 95,8 g.m $\mathrm{m}^{-2}$, respectivamente. A tampa e o fundo de todas as latas apresentavam praticamente o mesmo valor de camada seca de verniz, 12,1 g.m $\mathrm{m}^{-2}$ e 7,0 g.m ${ }^{-2}$, respectivamente.

\subsection{Métodos}

\section{Determinação da concentração de ácido ascórbico}

O método para a avaliação do conteúdo de ácido ascórbico do suco de maracujá baseou-se em uma adaptação da metodologia descrita por LAM, HOLCOMB e FUSARI ${ }^{11}$. Para tanto, foi utilizado um cromatógrafo marca Shimadzu, modelo Class-LC10, com bomba binária para gradiente de solventes, sistema de injeção tipo Rheodyne, modelo 7125, munido com alça de amostragem de $20 \mu \mathrm{L}$, detector de conjunto de diodos, com monitoração a $260 \mathrm{~nm}$. O registro e tratamento de dados foram feitos com uso de programa específico do equipamento Class-LC10. A concentração de ácido ascórbico foi determinada nas épocas de $0,15,180$ e 360 dias de estocagem a $25{ }^{\circ} \mathrm{C}$ e $35{ }^{\circ} \mathrm{C}$, em cinco replicatas.

\section{Avaliação da cor}

A avaliação instrumental da cor do suco de maracujá acondicionado nas diferentes embalagens estudadas, ao longo do tempo de estocagem $(0,15,30,60,120,180,240,300$ e 360 dias) nas duas condições de temperatura de estocagem de $25{ }^{\circ} \mathrm{C}$ e $35{ }^{\circ} \mathrm{C}$, foi realizada utilizando-se um colorímetro marca Macbeth, modelo Color Eye 2020, operando em software COMCOR1500Plus, obtendo-se os valores de L* (luminosidade), a* (vermelho), -a* (verde), b* (amarelo) e -b*(azul) ${ }^{6}$.

\section{Avaliação sensorial}

\section{Pré-seleção}

Inicialmente foi feita uma pré-seleção dos provadores através de entrevistas onde foram informados os objetivos gerais do estudo, tempo estimado de dedicação para a condução das sessões, freqüência dos testes e a necessidade da seleção e treinamento, a fim de se verificar quais os provadores interessados e com disponibilidade para participarem das avaliações.

\section{Seleção}

A seleção da equipe de provadores foi feita aplicando-se a análise seqüencial pelo teste triangular usando o procedimento tabular. Como a dissolução dos metais constituintes da lata, principalmente do ferro, é uma conseqüência das reações de interação lata/produto, que pode provocar o desenvolvimento de sabor metálico no suco, realizaram-se testes triangulares usando duas amostras de suco de maracujá pronto para beber, sendo um natural e outro adicionado de concentrações de ferro e estanho conhecidas, o qual foi preparado através do contato de placas de folha-de-flandres, sem revestimento polimérico e com cortes de aproximadamente $2 \mathrm{~mm}$ por todo seu comprimento, por um período de 20 dias a $40{ }^{\circ} \mathrm{C}$, com suco concentrado de maracujá.

Após o contato, os teores de ferro e estanho migrados para o suco foram quantificados no suco de maracujá concentrado pelo método de digestão ácida a quente em sistema fechado de digestão por microondas, marca CEM, modelo MARS 5. Os teores dos metais foram quantificados em espectrômetro

Tabela 1. Descrição do envernizamento interno das latas eletrossoldadas e nomenclatura adotada para o estudo.

\begin{tabular}{cccc}
\hline \multirow{2}{*}{ Nomenclatura } & & \multicolumn{2}{c}{ Tipo de Verniz } \\
\cline { 2 - 4 } & Tampa & Fundo & Corpo \\
\hline Normal & Organossol & Epóxi & Epóxi-fenólico \\
\hline Repair & Organossol & Epóxi-vinílico-acrilado & Epóxi-fenólico \\
\cline { 2 - 4 } & & Epóxi-vinílico-acrilado & Segunda camada de verniz epóxi modificado, líquido, \\
& & & Eplicação por spray após a formação da lata \\
\hline Pó & Organossol & Epóxi & Poliéster em pólico \\
\hline
\end{tabular}


de emissão atômica induzida por plasma com detector óptico (ICP-OES), marca Perkin Elmer, modelo OPTIMA 2000DV ${ }^{14}$.

O grau de dificuldade na identificação da amostra diferente foi determinado pela concentração de ferro adicionado ao suco pronto para beber, o qual foi reduzido até que fosse possível selecionar provadores com um número de respostas corretas igual ou superior a $80 \%$. Atingido este valor, foram aplicadas sete séries de testes triangulares, com a mesma condição, selecionando-se os candidatos que alcançaram um número significativo de respostas corretas, superior a $60 \%$ de acertos em todos os testes ${ }^{2,7}$. Foram selecionados 15 provadores, sendo 9 mulheres e 6 homens, com idades entre 18 e 41 anos.

\section{Treinamento}

O treinamento da equipe foi conduzido pelo método da análise descritiva quantitativa (ADQ), utilizando-se escala linear não estruturada de $9 \mathrm{~cm}$ de comprimento e extremidades fixas $^{13}$. Os atributos sensoriais estabelecidos e definidos em conjunto com os provadores foram aroma, sabor (maracujá, ácido, doce, amargo, oxidado, aguado, estranho e residual) e perda da qualidade.

\section{Análise sensorial periódica}

A avaliação sensorial periódica dos produtos acondicionados nos três diferentes tipos de embalagem, estocadas nas condições de temperatura de $25^{\circ} \mathrm{C}$ e $35^{\circ} \mathrm{C}$, juntamente com a referência acondicionada em embalagem cartonada, foi realizada nas épocas de $0,15,30,60,120,180,240,300$ e 360 dias de estocagem, sendo que a boa qualidade sensorial do suco, observada ao término dos 360 dias de estocagem, permitiu estender a avaliação por mais 60 dias, totalizando 420 dias de estocagem. O método aplicado na avaliação sensorial foi de análise descritiva quantitativa (ADQ), utilizando-se escala linear não estruturada de $9 \mathrm{~cm}$ de comprimento e extremidades fixas ${ }^{13}$.

\section{Teste de Aceitação}

Ao término do estudo (420 dias de estocagem) foi aplicado um teste de aceitação às amostras de suco de maracujá reprovadas pelos provadores treinados, que atribuíram notas próximas a 4,5 (50\% do fundo da escala) no atributo perda da qualidade, a fim de verificar a aceitação do suco por consumidores não treinados. As amostras reprovadas no estudo de estabilidade e avaliadas pelo teste de aceitação foram os sucos das latas Pó $25{ }^{\circ} \mathrm{C}$, Pó $35{ }^{\circ} \mathrm{C}$ e Repair $25^{\circ} \mathrm{C}$, tendo sido solicitado aos provadores que indicassem o quanto gostaram ou desgostaram das amostras ${ }^{2,7}$. O teste foi realizado com 50 provadores, sendo 40 mulheres e 10 homens.

\section{Análise estatística}

Os resultados obtidos nas avaliações periódicas do suco foram avaliados estatisticamente para cada tipo de embalagem, ao longo do tempo de estocagem nas duas condições de temperatura, através de análise de variância (ANOVA), ao nível de erro de $5 \%$, a fim de avaliar os efeitos da temperatura, do tempo de estocagem e do tipo de revestimento interno, assim como a existência de possíveis efeitos de interação entre esses fatores. Para tanto, utilizou-se o programa Statistica versão 5.0.

\section{Resultados e discussão}

\subsection{Determinação do conteúdo de ácido ascórbico (vitamina C)}

A Tabela 2 e a Figura 1 apresentam os resultados obtidos na determinação da concentração de ácido ascórbico (vitamina C) do suco de maracujá acondicionado nos três tipos de latas, demonstrando o comportamento desta vitamina durante o período de estocagem do produto.

A concentração de ácido ascórbico determinado ao zero dia de estocagem nas três embalagens apresentou-se semelhante, havendo um acentuado decréscimo ao longo dos 180 dias iniciais, mantendo-se estável até os 360 dias de estocagem nas duas temperaturas e para todos os tipos de latas. Foram verificadas diferenças significativas $(p<0,05)$ entre as temperaturas de estocagem, porém não foram verificadas diferenças significativas entre os três sistemas de envernizamento interno avaliados.

A degradação do ácido ascórbico ao longo do tempo de estocagem deve-se provavelmente à concentração de oxigênio presente no espaço livre das latas, a qual se apresentou semelhante para as três embalagens (média de 14\%), ao teor de oxigênio dissolvido no produto, além da dissolução de íons ferro, presentes no material metálico, levando à perda do conteúdo da vitamina $\mathrm{C}$.

Também se observou um decréscimo mais acentuado da concentração de ácido ascórbico no produto condicionado à temperatura de $35{ }^{\circ} \mathrm{C}$ quando comparado ao condicionado a $25^{\circ} \mathrm{C}$, que demonstrou o efeito de aceleração da degradação do ácido ascórbico pela estocagem à temperatura mais elevada ${ }^{5}$.

Tabela 2. Concentração de ácido ascórbico do suco de maracujá acondicionado nas latas Normal, Repair e Pó, em mg ácido ascórbico.100 mL ${ }^{-1}$.

\begin{tabular}{|c|c|c|c|c|c|c|c|}
\hline \multicolumn{2}{|c|}{ Concentração $\left(\mu \mathrm{g} \cdot \mathrm{kg}^{-1}\right)$} & \multicolumn{2}{|c|}{ Normal } & \multicolumn{2}{|c|}{ Repair } & \multicolumn{2}{|c|}{ Pó } \\
\hline & & $25^{\circ} \mathrm{C}$ & $35^{\circ} \mathrm{C}$ & $25^{\circ} \mathrm{C}$ & $35^{\circ} \mathrm{C}$ & $25^{\circ} \mathrm{C}$ & $35^{\circ} \mathrm{C}$ \\
\hline \multirow[t]{2}{*}{ Inicial } & Média & $15,00^{\mathrm{a}}$ & $15,00^{\mathrm{b}}$ & $15,98^{\mathrm{a}}$ & $15,98^{b}$ & $16,10^{\mathrm{a}}$ & $16,10^{\mathrm{b}}$ \\
\hline & Desvio & 0,04 & 0,04 & 0,11 & 0,11 & 0,04 & 0,04 \\
\hline \multirow[t]{2}{*}{ Final } & Média & $9,39^{\mathrm{a}}$ & $5,96^{\mathrm{b}}$ & $7,91^{\mathrm{a}}$ & $5,25^{\mathrm{b}}$ & $8,58^{\mathrm{a}}$ & $4,67^{b}$ \\
\hline & Desvio & 0,06 & 0,10 & 0,29 & 0,09 & 0,06 & 0,16 \\
\hline \multicolumn{2}{|c|}{ Perda de Vitamina C (\%) } & 37,4 & 60,3 & 50,5 & 67,1 & $46,7^{*}$ & 71,0 \\
\hline
\end{tabular}

Média de 5 determinações; *quando comparado o teor de ácido ascórbico determinado aos 180 dias de estocagem, a perda de Vitamina C equivale a $60,2 \%$; e médias acompanhadas pela mesma letra, na mesma linha e mesma temperatura, não diferem significativamente entre si pela análise de variância ao nível de erro de $5 \%$. 

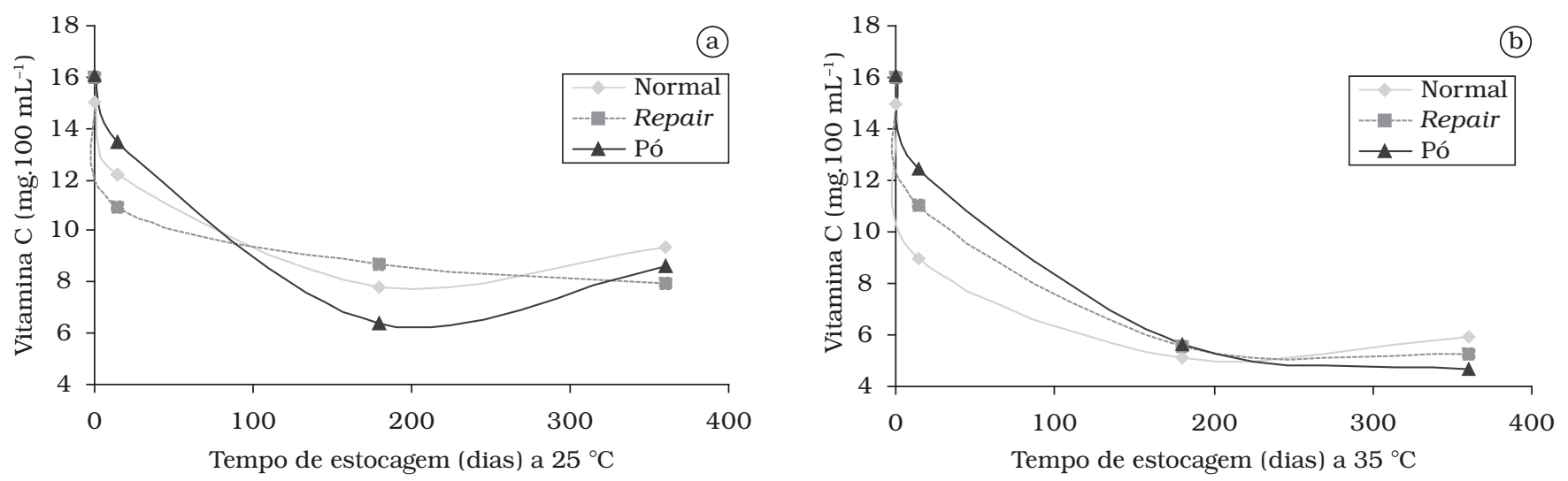

Figura 1. Perda de vitamina $\mathrm{C}$ no suco de maracujá durante o estudo: a) suco condicionado a $25^{\circ} \mathrm{C}$ e b) $35^{\circ} \mathrm{C}$.

\subsection{Avaliação da cor}

Os resultados obtidos na avaliação instrumental de cor, luminosidade $\left(\mathrm{L}^{*}\right)$, vermelho $\left(\mathrm{a}^{*}\right)$ e amarelo $\left(\mathrm{b}^{*}\right)$, do suco de maracujá acondicionado nas latas com diferentes sistemas de envernizamento interno, para as duas condições de estocagem, são apresentados nas Figuras 2 a 4.

Em análise estatística ANOVA, realizada para os parâmetros luminosidade, vermelho e amarelo, para os resultados
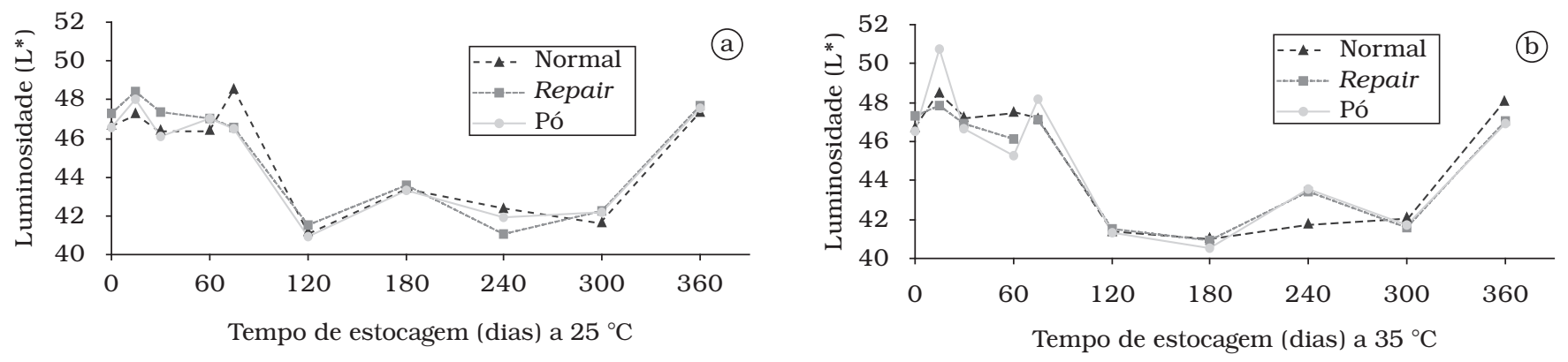

Figura 2. Evolução do parâmetro luminosidade ( $\left.\mathrm{L}^{*}\right)$ na avaliação do suco de maracujá acondicionado nos três tipos de latas a) $25^{\circ} \mathrm{C}$; e b) $35^{\circ} \mathrm{C}$.
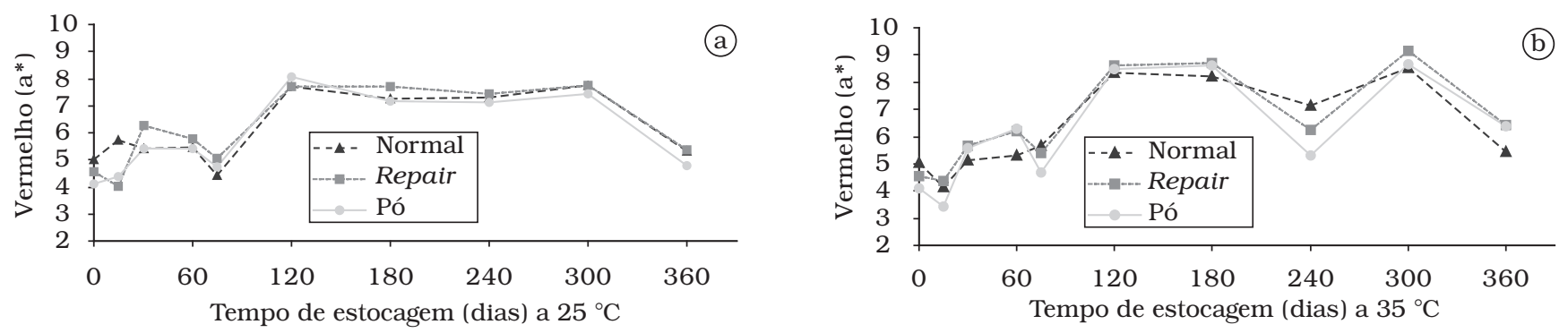

Figura 3. Evolução do parâmetro vermelho (a*) na avaliação do suco de maracujá acondicionado nos três tipos de latas a) $25^{\circ} \mathrm{C}$; e b) $35^{\circ} \mathrm{C}$.
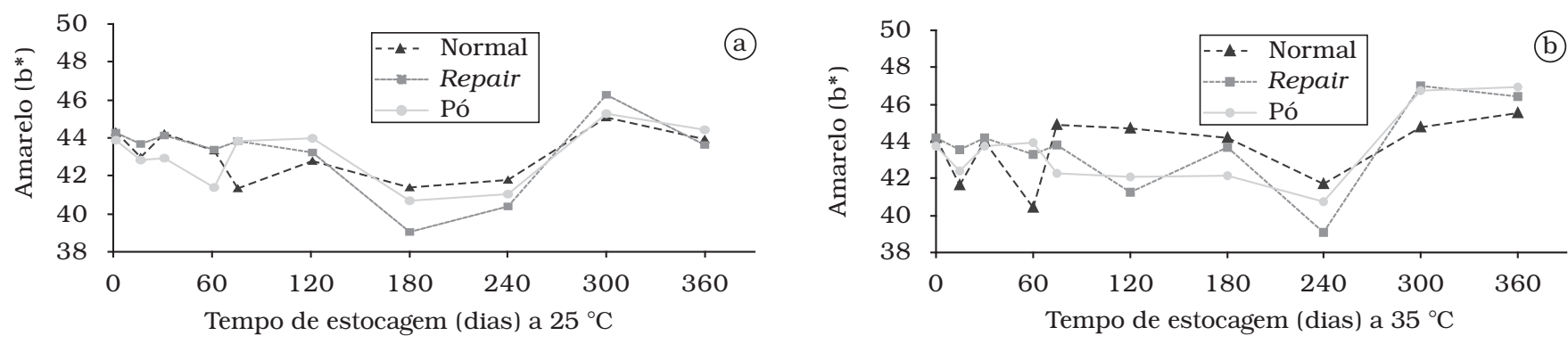

Figura 4. Evolução do parâmetro amarelo ( $\left.\mathrm{b}^{*}\right)$ na avaliação do suco de maracujá acondicionado nos três tipos de latas a) $25^{\circ} \mathrm{C}$; e b) $35^{\circ} \mathrm{C}$. 
obtidos durante os 360 dias de estocagem do suco, verificou-se que foi significativo $(\mathrm{p}<0,05)$ o efeito do tempo de estocagem na alteração dos parâmetros de cor avaliados. Não foi observada diferença significativa entre os três sistemas de envernizamento interno e entre as temperaturas.

A partir dos 120 dias de estocagem ocorreu um decréscimo da luminosidade e um aumento do vermelho e do amarelo, mantendo-se estável entre os 120 e 300 dias de estocagem, como observado nas Figuras 2 a 4, indicando o escurecimento do suco, provavelmente associado às alterações ocasionadas ao ácido ascórbico. Nas fases finais de decomposição do ascorbato há formação de compostos ou precursores de sabor, que resultam na formação de pigmentos de cor caramelo, os quais contribuem para o escurecimento não enzimático ${ }^{5,9}$.

Posteriormente, entre os 300 e 360 dias de estocagem, houve um aumento da luminosidade e decréscimo do vermelho e do amarelo, indicando a descoloração do suco, a qual já era esperada como resultado das possíveis alterações de degradação dos carotenóides. Os carotenóides são compostos lipossolúveis moderadamente estáveis ao calor e sujeitos à perda de cor por oxidação, sendo facilmente catalisados pela presença de duplas ligações em sua cadeia. Em processos que envolvem tratamento térmico, como no caso do suco estudado, o $\beta$-caroteno sofre isomerização da forma trans para cis. A formação dos isômeros cis por vezes não afeta a cor do produto, mas sim a atividade pró-vitamínica deste composto, alterando as características nutricionais do produto. A degradação do $\beta$-caroteno, que resulta em alteração de cor, também é esperada quando se submete o produto a longo tempo de estocagem ${ }^{1,5}$.

Apesar do desempenho similar do parâmetro cor entre os produtos acondicionados nos três diferentes sistemas de envernizamento interno, sabe-se que íons metálicos, como o ferro proveniente do material da embalagem, agem como catalisadores de processos oxidativos em compostos como os carotenóides presentes no suco, que caracterizam a cor do produto.

\subsection{Avaliação sensorial periódica}

Os resultados da avaliação sensorial dos atributos de aroma, sabor e perda da qualidade do suco de maracujá acondicionado nas diferentes latas e temperaturas e do suco referência, nas épocas inicial e final de estocagem, são apresentados nos gráficos da Figura 5.

A análise estatística $(\mathrm{p}<0,05)$ dos resultados obtidos para os atributos sensoriais, avaliando as interações entre os tipos de latas, tempo e temperatura de estocagem, mostrou que os efeitos do tempo e da temperatura influenciaram na alteração de todos os atributos avaliados no suco durante o período de estocagem.

Os resultados dos atributos avaliados durante os 420 dias de estocagem indicaram que o suco de maracujá apresentou perda de aroma, sabor característico e qualidade global nas três latas, principalmente à temperatura de $35^{\circ} \mathrm{C}$, mantendo, no entanto, a qualidade global aceitável para consumo.
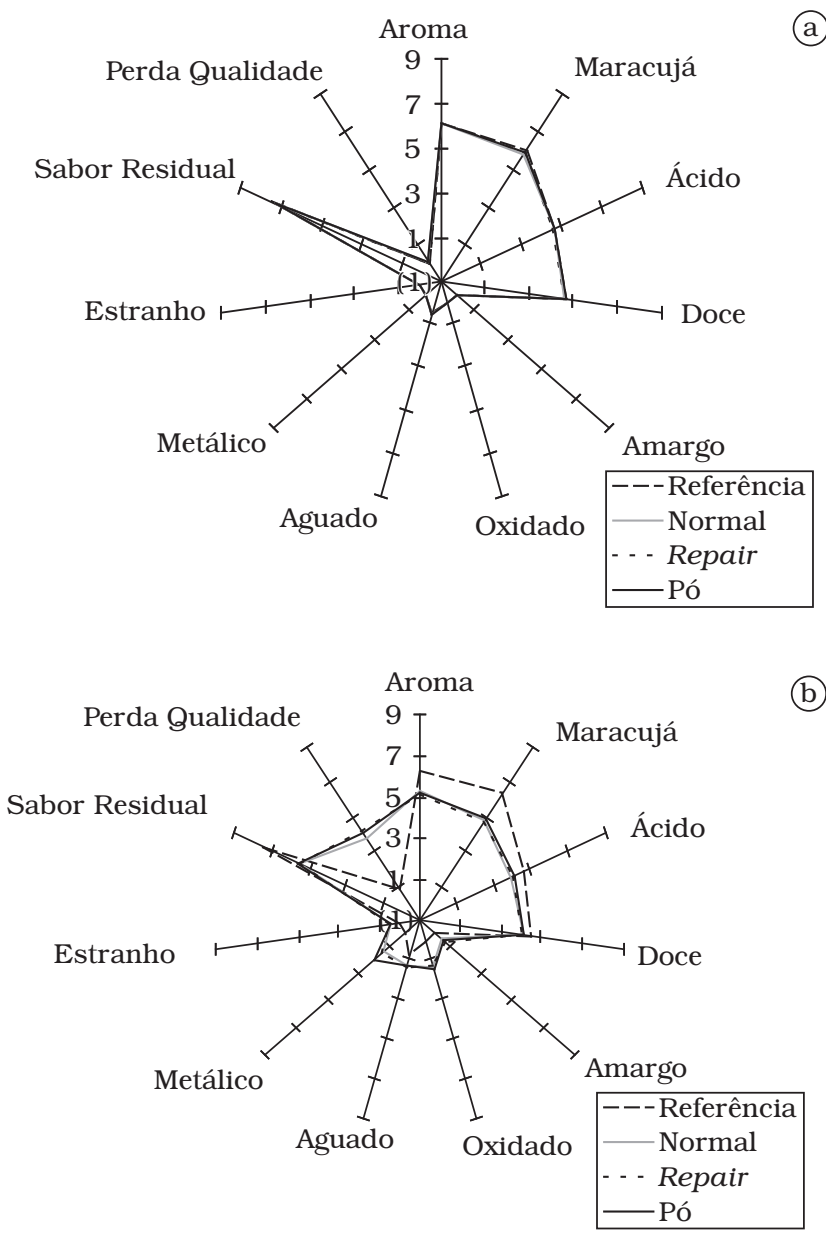

(b)

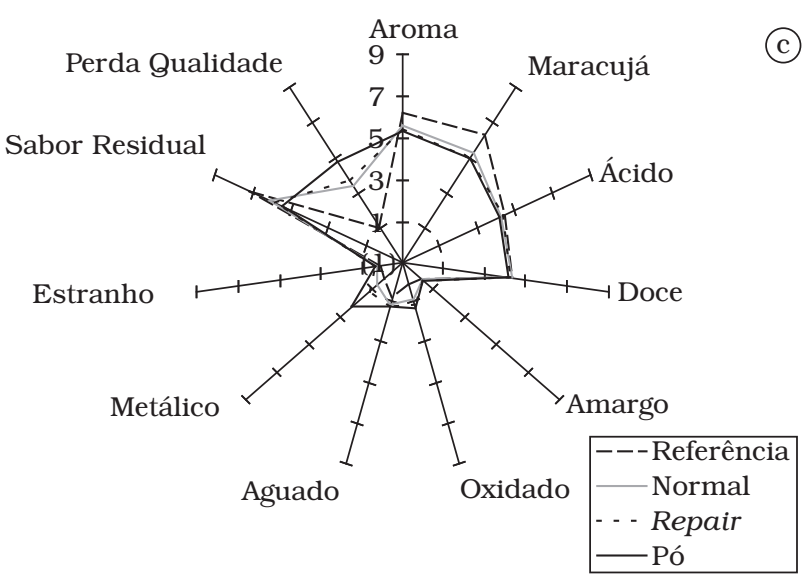

Figura 5. Avaliação sensorial do suco de maracujá acondicionado em latas com três tipos de envernizamento interno e do suco referência (estocado a $-20{ }^{\circ} \mathrm{C}$ ) a) 0 dias; b) 420 dias a $25^{\circ} \mathrm{C}$; e c) $35^{\circ} \mathrm{C}$.

O limite mínimo de percepção do sabor metálico no suco de maracujá pronto para beber pela equipe de provadores treinados foi de $20 \mathrm{mg} \cdot \mathrm{kg}^{-1}$ (ppm) de ferro. Os teores deste metal determinados no suco de maracujá aos 360 dias de estocagem estavam na ordem de $15 \mathrm{mg} . \mathrm{kg}^{-1}$ (ppm), os quais eram inferiores aos percebidos pelos provadores treinados. Apesar dos teores de metais apresentarem-se baixos, os provadores atri- 
buíram notas mais elevadas para este atributo, principalmente para os sucos da lata Pó $\left(2,2\right.$ para $35^{\circ} \mathrm{C}$ e 1,9 para $\left.25^{\circ} \mathrm{C}\right)$.

O desempenho inferior da lata Pó em relação a este parâmetro, observado em relação às demais latas, provavelmente foi associado à menor camada de verniz aplicada no corpo e também pela ocorrência de defeitos verificados na solda elétrica. Estes defeitos podem ter ocorrido pela produção das latas Pó em escala piloto, diferente das demais, que não permitiu realizar um controle eficiente da condição de soldagem antes da aplicação do verniz em Pó, acarretando a exposição metálica e propiciando, assim, as reações de interação lata/produto e conseqüentemente maior dissolução metálica.

Os resultados da determinação de metais nos sucos e da avaliação do atributo sabor metálico indicaram que as notas de perda de qualidade atribuídas ao suco de maracujá, na avaliação sensorial realizada ao final da estocagem, provavelmente ocorreram em função da degradação natural das características iniciais do próprio suco e não pelo desenvolvimento de sabor metálico.

A presença de sabores estranhos no suco foi percebida por alguns provadores, sendo que quando identificados foram denominados como sabores de "suco cozido" ou "fruta passada". Essa percepção ocorreu para os produtos de todos os tipos de latas e condições de estocagem, sendo provavelmente atribuídos aos sucos devido à perda do frescor em relação à amostra referência.

De um modo geral, a avaliação sensorial demonstrou um desempenho similar para todas as latas, sendo um pouco inferior apenas na lata Pó. A avaliação estatística dos resultados $(\mathrm{p}<0,05)$ não demonstrou diferenças significativas entre os diferentes tipos de latas estudados ao longo dos 420 dias de estocagem.

\subsection{Teste de aceitação}

As amostras reprovadas pelos provadores treinados na avaliação sensorial e avaliadas pelo teste de aceitação foram os sucos das latas Pó $25^{\circ} \mathrm{C}$, Pó $35^{\circ} \mathrm{C}$ e Repair $25^{\circ} \mathrm{C}$, as quais receberam, respectivamente, notas $4,1,4,8$ e 4,2 para o atributo perda de qualidade. As latas Normal $25{ }^{\circ} \mathrm{C}$, Normal $35{ }^{\circ} \mathrm{C}$ e Repair $35^{\circ} \mathrm{C}$ receberam, respectivamente, notas $3,8,3,3$ e 3,7 para o atributo perda de qualidade.

Os resultados obtidos no teste de aceitação realizado por consumidores não treinados com as amostras Repair $25{ }^{\circ} \mathrm{C}$, Pó $25^{\circ} \mathrm{C}$ e Pó $35^{\circ} \mathrm{C}$ aos 420 dias de estocagem, estão apresentados na Tabela 3.

A avaliação estatística ANOVA $(\mathrm{p}<0,05)$ realizada nos resultados do teste de aceitação indicou que o suco acondi-

Tabela 3. Notas atribuídas no teste de aceitação para o suco de maracujá acondicionado nas latas Repair $25^{\circ} \mathrm{C}$, Pó $25^{\circ} \mathrm{C}$ e Pó $35^{\circ} \mathrm{C}^{1}$.

\begin{tabular}{lccc}
\hline & Repair $25^{\circ} \mathrm{C}$ & Pó $25^{\circ} \mathrm{C}$ & Pó $35^{\circ} \mathrm{C}$ \\
\hline Média & $6,63^{\mathrm{a}}$ & $6,61^{\mathrm{a}}$ & $5,14^{\mathrm{b}}$ \\
Desvio padrão & 1,70 & 1,86 & 1,86 \\
\hline
\end{tabular}

$\overline{\text { Escala com notas numéricas de preferência variando de (1) desgostei muitíssimo a (9) gostei }}$ muitíssimo; e médias acompanhadas pela mesma letra na mesma linha não diferem significativamente entre si pela análise de variância ao nível de erro de $5 \%$. cionado na lata Pó condicionada a $35{ }^{\circ} \mathrm{C}$ apresentou menor preferência, sendo rejeitada por $40,8 \%$ dos provadores. Em seguida encontra-se o suco acondicionado na lata Repair $25^{\circ} \mathrm{C}$, reprovada por $16,3 \%$ dos provadores e finalmente a amostra Pó $25{ }^{\circ} \mathrm{C}$, com reprovação de apenas $12,2 \%$ dos provadores.

\section{Conclusões}

O estudo realizado permitiu verificar que a degradação do ácido ascórbico (vitamina C) no suco de maracujá acondicionado nas latas de três peças em folha-de-flandres eletrossoldadas ocorreu principalmente nos primeiros 15 dias de estocagem, para ambas as temperaturas de estocagem e em todas as variáveis de envernizamento interno das latas, mantendo-se o teor desta vitamina praticamente constante a partir dos 180 dias de estocagem.

Foram observadas ligeiras alterações de cor no suco de maracujá ao longo do período de estocagem, caracterizadas por leve escurecimento do suco até 120 dias e posteriormente por uma leve descoloração entre os 300 e 360 dias de estocagem, os quais foram associados aos processos de degradação intrínsecos do suco, não sendo relacionados à interação do produto com a embalagem.

As avaliações sensoriais indicaram que ao término dos 360 dias previstos de estocagem, o suco apresentava boas condições de consumo, para todas as variáveis de temperatura e latas avaliadas, demonstrando que os três sistemas podem ser utilizados para acondicionamento de suco de maracujá pronto para beber, garantindo que, do ponto de vista de qualidade sensorial, a bebida apresente uma vida-de-prateleira mínima de um ano.

\section{Agradecimentos}

À Fundação de Apoio à Pesquisa do Estado de São Paulo (FAPESP) pelo suporte financeiro ao projeto.

Às pesquisadoras científicas Marta Gomes da Silva e Valéria Delgado Anjos do Instituto de Tecnologia de Alimentos pela colaboração na realização de ensaios no produto.

\section{Referências bibliográficas}

1. ALVES, R. M. et al. Stability of fruit juice drinks in aseptic packages. Packaging Technology and Science, West Sussex, v. 14 , n. 2, p. 79-86, mar./abr. 2001.

2. DANTAS, S. T. Desempenho de embalagens metálicas para bebidas carbonatadas: avaliação de latas fabricadas por soldagem elétrica frente às latas convencionais. 1987. 247 p. Dissertação (Mestrado em Ciência de Alimentos) - Faculdade de Engenharia de Alimentos, Universidade Estadual de Campinas - UNICAMP, Campinas, 1987.

3. DATAMARK. Sucos e néctares. Disponível em: <http://www. datamark.com.br>. Acesso em: 10 jul.2006. Atualizado em: jun. 2006.

4. FARIA, E. V. Avaliação do desempenho de latas de folhade-flandres por meio da espectroscopia de impedância eletroquímica e do acompanhamento da estocagem de palmito pupunha (Bactris gasipaes). 2000. 168 p. Tese (Doutor em Engenharia Mecânica) - Faculdade de Engenharia Mecânica, 
Universidade Estadual de Campinas - UNICAMP, Campinas, 2000.

5. FEnNEMA, O. R. Food chemistry. $3^{\text {rd }}$ ed. Madison: Marcel Dekker, Inc., 1996. 1067 p.

6. FERREIRA, V. L. P. Princípios e aplicações da colorimetria em alimentos. Campinas: ITAL, 1981. 85 p.

7. GARRUTI, R. S. Metodologia na seleção seqüencial e não seqüencial de provadores para análise sensorial de alimentos e bebidas. 1976. 211 p. Dissertação (Doutorado em Ciência de Alimentos) - Faculdade de Engenharia de Alimentos e Agrícola, Universidade Estadual de Campinas - UNICAMP, Campinas.

8. HABERLI, L. Sucos prontos para gerar lucro. Embalagem Marca, São Paulo v. 5., n. 45, p.16-22, maio 2003.

9. KACEM, B. et al. Nonenzymatic browning in aseptically packaged orange drinks: effects of ascorbic acid, amino acids, and oxygen. Journal of Food Science, v. 52, n. 6, p. 1668-1672, 1987.
10. LABRUNA, J. C. Sucos prontos: matam a sede do mercado. Engarrafador Moderno, São Paulo, v. 10, n. 84, p. 34-38, abr., 2001.

11. LAM, F. L.; HOLCOMB, I. J.; FUSARI, S. A. Liquid chromatography assay of ascorbic acid, niacinamide, piridoxine and riboflavine in mineral preparations. J. Assoc. of. Anal. Chem., v. 67, n. 5, p. 1007-1011, 1984.

12. MEDINA, J. C. et al. Maracujá: da cultura ao processamento e comercialização. Campinas: ITAL, 1980. 207 p. (Série Frutas Tropicais, 9).

13. MORAES. M. A. C. Métodos para avaliação sensorial dos alimentos. 7. ed. Campinas: UNICAMP, 1990. 93 p.

14. MORGANO, M. A.; QUEIROZ, S. C. N.; FERREIRA, M. M. C. Determinação dos teores de minerais em sucos de frutas por espectrometria de emissão óptica em plasma indutivamente acoplado (ICP-OES). Ciência e Tecnologia de Alimentos, v. 19, n. 3, set./dez. 1999 . 